\title{
Thermodynamic Analysis of Kalina Cycle
}

\author{
Moghees Ahmad', M. N. Karimi ${ }^{2}$ \\ ${ }^{1,2}$ Department of Mechanical Engineering, Faculty of Engineering, Jamia Millia Islamia, Delhi-25, India
}

\begin{abstract}
Efficient utilization of the low temperature heat is a challenge. Kalina cycle was proposed to exploit the opportunity of extracting this low grade energy as the conventional Rankine is very inefficient for low temperature applications. In this paper the energy analysis of the Kalina cycle is done. The maximum temperature for the cycle is varied between range $100-200^{\circ} \mathrm{C}$ and the sink temperature for the cycle is assumed as $27^{\circ} \mathrm{C}$ at the exit of the condenser. The model selected for this analysis is KCS-11 owing to its suitably for low temperature application. The pressure is varied between 20-50 bar in steps of 5 bar. The mass fraction of ammonia for composition of ammonia-water mixture is taken $70 \%$. The efficiency of the Kalina cycle is calculated and tabulated for the heat input of $2 \mathrm{MW}$ to the cycle. The results show that the efficiency of the cycle is solely a function of the separator vapour pressure which is a function of the temperature of the HRVG and has no effect of the HRVG pressure.
\end{abstract}

Keywords: Kalina cycle, energy analysis.

\section{Introduction}

With the ever-increasing population of the world, the power demand is also increasing proportionally but the resources i.e. the conventional fuels are depleting fast. The efforts are made to find alternate fuels which can cater to the rising demand of power. Different forms of non-conventional energy are now being utilized to address the rising demand such as OTEC (Ocean Thermal Energy Conversion), Geothermal Energy, Solar Thermal Energy, Wind Energy, Biomass etc.

Meanwhile there is a quest to efficiently utilize the resources we have at our disposal. The conventional power plants and the other industries have lot of waste energy i.e. Low Grade Heat Energy at low temperature, capturing this energy to produce power can not only mitigate energy shortage we are facing but also concurrently address the issue of global warming by preventing the waste heat discard to the atmosphere.

The Carnot cycle is the ideal cycle; it provides an upper limit on the efficiency that any classical thermodynamic engine can achieve during the conversion of thermal energy into work. Although this cycle is ideal for energy utilization but cannot be used as it is not practical to run this cycle. Therefore, other practical cycles are used to extract the energy from low temperature heat source.

The first candidate for utilization of this low temperature heat energy is Rankine Cycle, since Rankine Cycle has highest efficiency among the conventional power conversion cycle [1]. But for low temperature application Rankine cycle has very low efficiency. In order to extract power from this low temperature waste heat other cycles were proposed namely Organic Rankine Cycle (ORC) and the Kalina Cycle. For ORC, selection of fluid and the design of turbine (which is called Expander in ORC) is an important task for the ORC [2].

In the pursuit of utilizing low temperature heat, Kalina proposed a novel thermodynamic power cycle called Kalina Cycle, which exploited the properties of a binary mixture (ammonia-water) to capture low temperature heat and to efficiently utilize waste heat. The non-azeotropic behaviour of the binary mixture makes this cycle very formidable for low temperature heat recovery over other cycles. The thermodynamic analysis of this cycle is carried in this paper for low temperature applications.

\section{Literature Review}

Since the time this cycle was proposed it has been studied for a large range of applications such as Solar Thermal Power Generation, Bottoming Cycle in combined cycle power plants for low grade heat recovery, Geothermal Energy, and direct fired power plant as well, by Dr. Kalina himself [5,6,7].

Henry A. Mlcak [9] stated that Kalina power plant can be $30 \%$ less capital-intensive than the Rankine cycle power plant for low temperature application and up to $10 \%$ for direct fired application. Kalina demonstrated that his cycle has efficiency 30 to $60 \%$ higher than the steam cycles for low temperature application [3]. Kalina cycle has further advantage of operating above atmospheric pressure which prevent leakage of gases into the system which can mar the efficiency of a closed cycle [10,11]. El-Sayed and Tribus [12] compared the Kalina cycle with the Rankine cycle. Marston [13] carried out parametric analysis of Kalina cycle by modifying the previous models. When both cycles are used as a ,,,bottomingecee cycle with the same thermal boundary conditions, it can be found when the heat source is below $\left(537^{\circ} \mathrm{C}\right)$, the Kalina cycle may show 10 to $20 \%$ higher second law efficiencies than the simple Rankine cycle [14].

Ibrahim and Kovach [15] in their research concluded that the Kalina cycle reduces thermal pollution from condenser circulating water and reduces combustion by-products such as $\mathrm{SO}_{2}$. The Kalina cycle was also used to efficiently recover heat from solar energy. Ganesh et.al [16] showed that the Kalina cycle efficiency for solar energy recovery is $13 \%$. Xinguo Li et.al. [17] substituted throttle valve and absorber with ejector for Kalina Cycle System 11(KCS 11) and showed that the net power output and thermal efficiency is more than that with KCS 11. Jiacheng He et.al.[18] also replaced the throttle valve with a two phase expander and 


\section{International Journal of Science and Research (IJSR) \\ ISSN (Online): 2319-7064 \\ Index Copernicus Value (2013): 6.14 | Impact Factor (2014): 5.611}

compared it with KCS 11 and concluded that the efficiency is $27 \%$ more than that of the KCS 11 .

Binary fluid mixture also opened up the horizon for simultaneous power production as well as refrigeration. Goswami [19] proposed his new cycle named Goswami cycle to produce power and cooling effect from a single cycle in unison. Goswami with other researchers carried out thorough study of Goswami cycle by varying parameters and their effect on the efficiency $[20,21]$.

Apart from the conventional Kalina cycle, variants of the Kalina cycle are also proposed viz. Kalina Split-Cycle. In the Split-Cycle, the concentration of ammonia is varied throughout the evaporation process to obtain a matching temperature profile as that on the heat source. Ulrik Larsen et.al. [22] compared the conventional Kalina Cycle and Kalina Split-cycle and found that the Split-Cycle process can obtain an efficiency of $23.2 \%$ as compared to the conventional Kalina Cycle of $20.8 \%$. But at the same time, cost of installation also increases as the complexity increases. After thermal efficiency, Exergy analysis of the Kalina Split-Cycle was done by Tuong-Van Nguyen et.al [23] and found that the exergetic efficiency of the Kalina Split-Cycle is $2.8 \%$ more than the conventional Kalina cycle.

A comparative analysis between ORC and Kalina cycle to recover waste heat from Gas Turbine- Modular Helium Reactor (GT-MHR) by Zare and Mahmoudi [24] and concluded that for heat recovery from the Gas Turbine ORC is more efficient than the Kalina Cycle. Shokati et.al. [25] carried out parametric analysis of ORC and Kalina Cycle by varying ammonia concentration and operating pressure of the cycle. Shokati et.al also analysed the cycles exergoeconomically and optimized the cycle for improved performance output. In this paper ORC was found to produce more power although the cost of producing power is less for the Kalina cycle.

OguzArslan [26] carried out a case study to produce power from ten hot water springs of Simav Geothermal area. KCS34 was used to carry out this study and Arslan demonstrated that 41.2 MW can be generated from these Simav hot wells.

\section{Kalina Cycle}

Around 1980 Dr. Alexander Kalina proposed a novel thermodynamic power cycle called Kalina Cycle, it uses mixture of two fluids i.e. binary mixture as its working fluid [3]. There is a marked difference in Kalina Cycle from Rankine Cycle and ORC in that its condensation and evaporation takes place at variable temperature, which means there is no single boiling point temperature but a range of temperature for a particular pressure and composition. The advantage of having a gliding temperature phase change is that the temperature profile of the working fluid matches that of the heating gases in the HRVG and cooling fluid in the condenser which makes the heat transfer more efficient and reversible. In contrast to Kalina cycle, the conventional Rankine cycle has water as working fluid with constant phase change temperature as a result the temperature profiles in the boiler and the condenser do not complement resulting in losses and making the cycle highly irreversible. Kalina cycle unlike Rankine cycle, is not so simple but the power plant running on Kalina cycle have complex arrangement of different devices and are referred to as models. Models of Kalina cycle are designed depending upon the requirement for which it is meant to be utilized, hence for different applications the models differ.

\subsection{System Description}

This paper focuses the low temperature heat utilization from waste heat of industries; the model employed for low temperature application is Kalina Cycle System-11 (KCS11) which is typically used as bottoming cycle to the power plant. A Kalina cycle system 11 is shown in Figure 1. As evident from the figure the system is much more complex than that of the Rankine cycle, it has a number of other components/devices added to it to serve the complexities for low temperature application. The components which are added to simple Rankine cycle are regenerator, throttle valve, separator and absorber to make it suitable for low temperature recovery and has their own specific works to carry out. The waste heat from the low temperature source is transferred to the Kalina cycle plant through a heat exchanger called Heat Recovery Vapour Generator (HRVG). This waste heat is absorbed by the binary mixture which is the working fluid of the Kalina cycle. The temperature range selected for this analysis is $100-200^{\circ} \mathrm{C}$. The working fluid at the exit of the HRVG is in the two phase region (state 2) owing to low temperature heat source. The Separator is placed after the HRVG to separate liquid (state 5) and vapour (state 3), the working fluid in the vapour form is entered into the Turbine/Expander which extract work from the working fluid whereas the liquid working fluid from the Separator is routed to a heat exchanger called Regenerator. Regenerator heats the working fluid before the HRVG (state 1) while liquid form of working fluid from Separator (state 5) gives up heat energy to this cool mixture from pump (state 10). Ammonia-water mixture from Regenerator (state 6) is throttled to reduce its pressure (state 7) and mixed in the Absorber with the binary ammoniawater mixture from the turbine exit (state 4). Post Absorber (state 8) to remove the heat from the binary mixture, Condenser is installed which is also a heat exchanger. In Condenser the heat is removed from the mixture by the cooling water circulated through the Condenser and the liquid working fluid (state 9 ) is sucked by the pump.

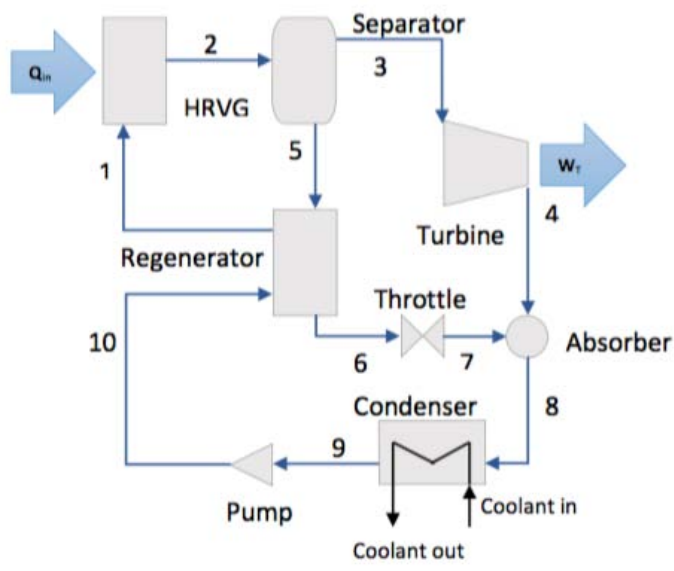

Figure 1: Kalina cycle system 11

\section{Volume 5 Issue 3, March 2016}




\section{International Journal of Science and Research (IJSR) \\ ISSN (Online): 2319-7064}

Index Copernicus Value (2013): 6.14 | Impact Factor (2014): 5.611

\subsection{Assumptions}

The assumptions are essential part of the analysis; conditions are assumed to simplify the analysis. The following are the main assumptions to study the model.

- Steady state operation of the cycle.

- Working fluid at the outlet of Condenser is saturated liquid.

- Working fluid at the inlet of the Turbine is saturated vapour.

- Temperature of the working fluid at the outlet of Condenser is $27^{\circ} \mathrm{C}$.

- Throttling process is isenthalpic.

- Separator completely separates the liquid and vapour.

- The isentropic efficiency of pump and turbine is $100 \%$.

- Pressure losses and heat losses in pipes are neglected.

- The effectiveness of the Heat Exchanger is $80 \%$.

- All the devices are adiabatic.

- The kinetic energy and potential energy changes in the devices are neglected.

\section{Cycle Performance Analysis}

The performance analysis of Kalina cycle is more rigorous than the conventional Rankine cycle owing to its complexity. Firstly, the added complexity to the cycle is because of the devices, the number of devices are increased as well as some of the devices are introduced into the cycle to cater to the unique requirement of the Kalina cycle such as Throttling device to reduce the pressure isenthalpically and the separator to separate the liquid and vapour phase of the binary working fluid. The absorber is used to mix high and low concentration binary working fluid and is placed after the turbine. Apart from these components/devices, the Kalina cycle system uses some well known devices such as Heat Exchanger (HRVG, Regenerator, and Condenser), Turbine, Pump. The thermodynamic analysis of these components are familiar and are a simple mass and energy balance task since the mass and energy are conserved. All the above devices are assumed to be steady flow devices, therefore steady state energy equation(SFEE) is applicable and after the assumption of neglecting the kinetic and potential energy changes, the equations are reduced to

$\sum \dot{\mathrm{m}}_{1}=\sum \dot{\mathrm{m}}_{\mathrm{o}}(1)$

$\sum \dot{\mathrm{Q}}+\sum \dot{\mathrm{m}}_{1} \mathrm{~h}_{\mathrm{i}}=\sum \dot{\mathrm{W}}+\sum \dot{\mathrm{m}}_{0} \mathrm{~h}_{\mathrm{r}}(2)$
The energy equations of all the devices used for the Kalina cycle are tabulated below.

Table 1: Energy Equations

\begin{tabular}{|c|c|}
\hline HRVG & $\dot{Q}=\dot{m}_{1} \times\left(h_{2}-h_{1}\right)$ \\
\hline Separator & $\dot{m}_{1} \times h_{2}=\dot{m}_{3} \times h_{3}+\dot{m}_{5} \times h_{5}$ \\
\hline Turbine & $W_{t}=\dot{m}_{3} \times\left(h_{3}-h_{4}\right.$ \\
\hline Regenerator & $\dot{m}_{1} \times\left(h_{1}-h_{9}\right)=\dot{m}_{5} \times\left(h_{5}-h_{6}\right)$ \\
\hline Throttle valve & $\dot{m}_{6} \times h_{6}=m_{10} \times h_{10}$ \\
\hline Pump & $W_{p}=v_{9} \times\left(p_{9}-p_{8}\right)$ \\
\hline Efficiency & $\eta=\frac{\mathrm{W}_{t}-\mathrm{W}_{p}}{\dot{Q}}$ \\
\hline
\end{tabular}

Secondly, the working fluid used in the Kalina cycle is binary non-azeotropic mixture of ammonia-water, a marked difference from the Rankine cycle. The properties and behaviour of this binary mixture is very different than that of a pure substance which is the working fluid for all other power plants. To calculate the properties specific enthalpy, entropy etc. of the mixture many researchers proposed empirical relations namely Peng-Robinson's, Patek and Klomfar among others. The professional software uses these equations to determine properties of the working fluid at various states at various states

\section{Results and Discussion}

The energy analysis of Kalina cycle was done for ammonia-water composition ratio .7/.3. The temperature range selected is $100-200^{\circ} \mathrm{C}$ as the study is for low temperature application. The pressure range is varied between $2 \mathrm{MPa}$ to $5 \mathrm{MPa}$ with steps of .5 MPa. For each of these pressures, the temperature is varied between 100 $200^{\circ} \mathrm{C}$ and the energy analysis of the cycle is carried out. In industries, the waste heat output is more or less same throughout the operation hence the heat input to the system is taken to be constant as $2 \mathrm{MW}$ for the analysis. The results obtained are shown in the Table 2 below. The table shows the calculated values for different pressure and temperature. The efficiencies for pressure and temperature are arranged in readable way as shown in the Table 2 . The efficiency of the KCS-11 is $1.6463 \%$ at $2 \mathrm{MPa}$ and $130^{\circ} \mathrm{C}$ increases steadily to $14.9837 \%$ as the pressure and temperature is increased.

Table 2: Efficiency for different Temperatures and Pressures

\begin{tabular}{|c|c|c|c|c|c|c|c|c|}
\hline & \multicolumn{7}{|c|}{ Temperature $\left({ }^{\circ} \mathrm{C}\right)$} \\
\hline & & 130 & 140 & 150 & 160 & 170 & 180 & 190 \\
\hline \multirow{7}{*}{ 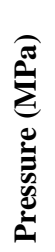 } & 2 & 1.6463 & 4.88 & 6.8973 & 8.9147 & & & \\
\hline & 2.5 & 1.6721 & 4.9673 & 6.9464 & 8.9255 & 11.1787 & & \\
\hline & 3 & 1.6541 & 4.786 & 6.8555 & 8.9251 & 11.1233 & & \\
\hline & 3.5 & 1.5962 & 4.876 & 6.999 & 9.1221 & 11.2768 & 12.9699 & \\
\hline & 4 & 1.6543 & 4.9851 & 7.0543 & 9.1235 & 11.0691 & 12.8784 & \\
\hline & 4.5 & 1.5632 & 4.9321 & 6.9792 & 9.0263 & 11.0448 & 12.8666 & 14.9847 \\
\hline & 5 & & 4.7876 & 6.83705 & 8.8865 & 11.1 & 12.8537 & 14.9839 \\
\hline
\end{tabular}

The results obtained from the analysis of the Kalina cycle are tabulated above and can be plotted on the efficiency vs temperature graph for different pressures as shown in
Figures below. The temperature is on abscissa and the efficiency is on ordinate. The variation of the efficiency with temperature is shown for different sets of pressures on 


\section{International Journal of Science and Research (IJSR) \\ ISSN (Online): 2319-7064}

Index Copernicus Value (2013): 6.14 | Impact Factor (2014): 5.611

the graph. Figure 2 shows the efficiency curve for pressure 2 and $2.5 \mathrm{MPa}$ in the temperature range $130-160^{\circ} \mathrm{C}$.

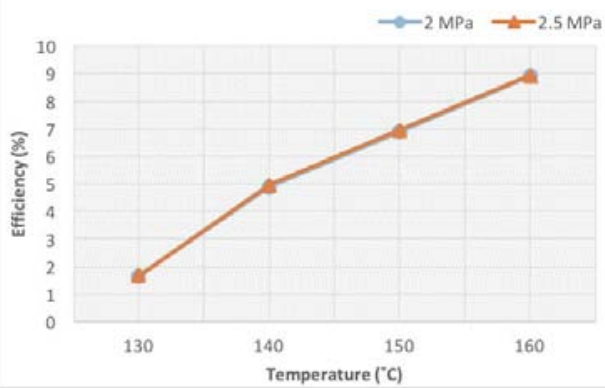

Figure 2: Efficiency vs Temperature at 2 \& $2.5 \mathrm{MPa}$

The efficiency shows an increasing trend as the temperature increases from $1.6463 \%$ at temperature $130^{\circ} \mathrm{C}$ to $8.9147 \%$ at temperature $160^{\circ} \mathrm{C}$. Now on increasing the pressure for the same temperature The efficiency of the cycle is solely a function of the temperature of the HRVG and not the function of the pressure of the HRVG. For a given temperature, the pressure of the separator is fixed irrespective of the pressure of the HRVG. For a particular temperature, varying the HRVG pressure varies the enthalpy of the mixture at the HRVG exit. Varying the pressure for a particular temperature also changes the amount of mass flow through the system and the dryness fraction as well. The overall variations are synchronized in such a way that for a particular temperature the efficiency remains same. Conversely it can also be observed that to utilize a particular temperature we have a range of pressures within which we can run the cycle, if the pressure is increased or decreased beyond that limit then the particular temperature cannot be maintained at the exit of the HRVG.

For the pressure $2.5 \& 3 \mathrm{MPa}$, the efficiency is calculated up to $170^{\circ} \mathrm{C}$ and is plotted on the graph shown below in Figure 3.

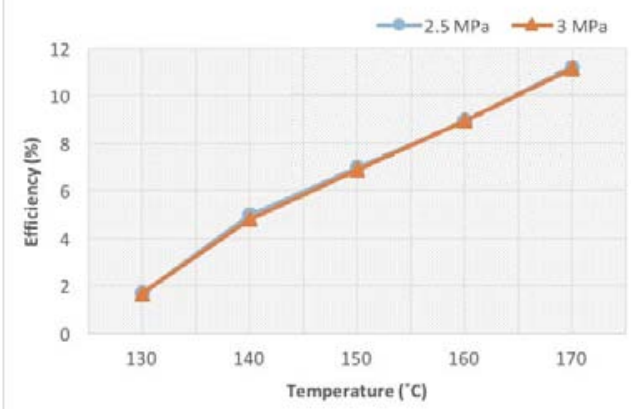

Figure 3: Efficiency vs Temperature at 2.5 \&3 MPa

As also evident in this graph as well that the efficiency has an increasing trend with coinciding values of efficiency irrespective of HRVG pressure.

Further the HRVG pressure is increased and energy analysis was carried out for different temperatures up to a ceiling value of $180^{\circ} \mathrm{C}$ because increasing temperature further heats up the working fluid to superheated state which renders the model inapplicable. This time the pressure selected is $3.5 \& 4 \mathrm{MPa}$, the efficiency increases to
$12.9699 \%$.

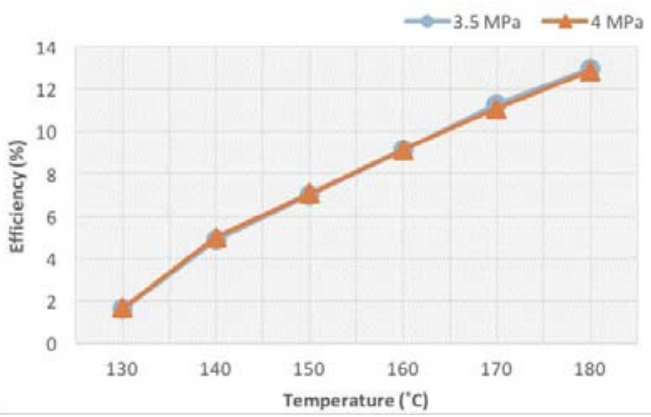

Figure 4: Efficiency vs Temperature at 3.5 \& $4 \mathrm{MPa}$

As the temperature increases the efficiency is increasing steadily, therefore to further increases the temperature of the Kalina cycle for KCS-11, the pressure is increased to $4.5 \& 5 \mathrm{MPa}$ and the cycle temperature goes to a value of $190^{\circ} \mathrm{C}$. The efficiency for this pressure and temperature further goes up to $14.9847 \%$ and is plotted in the Figure 5.



Figure 5: Efficiency vs Temperature at $4.5 \& 5 \mathrm{MPa}$

The above figures show that efficiency of the Kalina cycle increases as the temperature of the HRVG increases, in our case maximum efficiency $14.9847 \%$ is at temperature $190^{\circ} \mathrm{C}$ while the variation of the HRVG pressure has not changed the efficiency of KCS-11. The efficiency is purely a function of the exit temperature of the HRVG. The variation of the pressure has no effect on the efficiency as long as the temperature is kept constant at the exit of the HRVG. Although the enthalpy of the working fluid increases with increase of the pressure but there are variations in other parameters as well viz. dryness fraction, mass flow rate. For a particular temperature, the pressure of the vapour at the exit of the separator is fixed and the change of the pressure of the HRVG has no effect on the vapour pressure at the separator exit or turbine inlet pressure, it is purely a function of the temperature only. The variation of the dryness fraction and the mass flow rate are adjusted in a way so that the other change in properties of the working fluid gets adjusted.

\section{Conclusions}

The efficiency of the cycle is solely a function of the temperature of the HRVG and not the function of the 


\section{International Journal of Science and Research (IJSR) \\ ISSN (Online): 2319-7064 \\ Index Copernicus Value (2013): 6.14 | Impact Factor (2014): 5.611}

pressure of the HRVG. For a given temperature, the pressure of the separator is fixed irrespective of the pressure of the HRVG. For a particular temperature, varying the HRVG pressure varies the enthalpy of the mixture at the HRVG exit. Varying the pressure for a particular temperature also changes the amount of mass flow through the system and the dryness fraction as well. The overall variations are synchronized in such a way that for a particular temperature the efficiency remains same. Conversely it can also be observed that to utilise a particular temperature we have a range of pressures within which we can run the cycle, if the pressure is increased or decreased beyond that limit then the particular temperature cannot be maintained at the exit of the HRVG.

\section{Nomenclatures}

HRVG Heat Recovery Vapour Generator

KCS Kalina cycle system

$\dot{\mathrm{Q}}_{\mathrm{i}}$ Heat input to HRVG

$\dot{\mathrm{m}}$ Mass flow rate of working fluid, $\mathrm{kg} / \mathrm{s}$

$\mathrm{h}$ Enthalpy, $\mathrm{KJ} / \mathrm{kg}$

$\mathrm{W}_{\mathrm{p}}$ Workdone by pump, KW

$\mathrm{V}_{\mathrm{c}}$ Specific volume of the working fluid at the exit of the pump, $\mathrm{m}^{3} / \mathrm{kg}$

P Pressure

$\mathrm{T}$ Temperature

$\mathrm{W}_{\mathrm{p}}$ Workdone by turbine, KW

$\eta$ Efficiency, \%

\section{References}

[1] Rachel Anne Victor, Jin-Kuk Kim, Robin Smith; Composition optimization of working fluids for Organic Rankine Cycles and Kalina cycles, Energy 55 (2013) 114-126.

[2] Kalina AI. Combined-cycle system with novel bottoming cycle. ASME Journal of Engineering for Gas Turbine Power 1984; 106(4):737-42.

[3] Kalina AI, Leibowitz H, System design and experimental development of the Kalina cycle technology. In: Industrial Energy Technology Conference, Texas, USA 1987. p. 258.

[4] Kalina AI, Power cycle and system for utilizing moderate and low temperature heat sources. US Patents 6910334B2; Feb. 3, 2004.

[5] Kalina AI. Kalina cycles and system for direct-fired power plants, second Law analysis e industrial and environmental applications. ASME 1991; 25:41-7.

[6] Kalina AI, Leibowitz HM. Application of the Kalina cycle technology to geothermal power generation. Geothermal Resource Council Trans 1989;13: 605-11.

[7] Kalina AI, Liebovitz HM. Kalina cycle promises improved efficiency. Mod Power System (MPS) Rev 1987;7(1):19-23.

[8] Kalina AI, Tribus M, El-Sayed YM. A theoretical approach to the thermo- physical properties of two miscible- component mixtures for the purpose of powercycle analysis. ASME Paper 1986. 86-WA/HT-54.

[9] Henry A. Mlcak, PE, An Introduction to the Kalina Cycle, PWR- Vol. 30, Proceedings of the International
Joint Power Generation Conference Editors: L Kielasa, and G. E. Weed Book No. H01077 -1996.

[10]Kalina, A. Combined Cycle Waste Heat Recovery Power Systems Based on a Novel Thermodynamic Energy Cycle Utilizing Low-Temperature Heat for Power Generation. In Proceeding of the ASME Joint Power Generation Conference, Indianapolis, IN, USA, 25 September 1983; Paper 83-JPGC-GT-3. Available online: http://www.aidic.it/cet/13/35/037.pdf.

[11] Tamm, G.; Goswami, D.Y.; Lu, S.; Hasan, A.A. Theoretical and experimental investigation of an ammonia-water power and refrigeration thermodynamic cycle. Solar Energy 2004, 76, 217-228.

[12] Zamfirescu, C.; Dincer, I. Thermodynamic analysis of a novel ammonia-water trilateral Rankine cycle. Thermochim. Acta 2008, 477, 7-15.

[13]Y. M. El-sayed, and M. Tribus, A theoretical comparison of Rankine and Kalina cycles, ASME publication AES, Vol. 1 (1995).

[14] C. H. Marston, Parametric analysis of the Kalina cycle. ASME Journal of Engineering for Gas Turbine and Power 112, 107-116 (1990).

[15] Mounir B. Ibrahim, Ronald M. Kovach “A Kalina cycle application for power generation” Energy Volume 18, Pages 961-969.

[16] Ganesh NS, Srinivas T. Design and modelling of low temperature solar thermal power station. Application Energy 2012; 91: 180-6.

[17] Xinguo Li, Qilin Zhang, Xiajie Li, A Kalina cycle with ejector, Energy 54 (2013), 212-219.

[18]Jiacheng He, Chao Liu, Xiaoxiao Xu, Yourong Li, Shuangying $\mathrm{Wu}$, Jinliang $\mathrm{Xu}$, Performance research on modified KCS (Kalina cycle system) 11 without throttle valve, Energy 64 (2014) 389-397.

[19] Xu F, Goswami DY, Bhagwat SS. A combined power/cooling cycle. Energy 2000; 3:233-46.

[20] Tamm G, Goswami DY, Lu S, Hasan AA. Theoretical and experimental investigation of an ammonia water power and refrigeration thermodynamic cycle. Sol Energy 2004;76(1-3): 217-28.

[21] Padilla RV, Demirkaya G, Goswami DY, Stefanakos E, Rahman MM. Analysis of power and cooling cogeneration using ammonia-water mixture. Energy 2010; 35: 4649-57.

[22] Ulrik Larsen, Tuong-Van Nguyen, Thomas Knudsen, Fredrik Haglind, System analysis and optimisation of a Kalina split-cycle for waste heat recovery on large marine diesel engines, Energy 64 (2014) 484-494.

[23] Tuong-Van Nguyen, Thomas Knudsen, Ulrik Larsen, Fredrik Haglind, Thermodynamic evaluation of the Kalina split-cycle concepts for waste heat recovery applications, Energy 71 (2014) 277-288.

[24] V. Zare, S.M.S. Mahmoudi, A thermodynamic comparison between organic Rankine and Kalina cycles for waste heat recovery from the Gas Turbine-Modular Helium Reactor, Energy 79 (2015) 398-406

[25] NaserShokati, FaramarzRanjbar, MortazaYari, Exergoeconomic analysis and optimization of basic, dual-pressure and dual-fluid ORCs and Kalina geothermal power plants: A comparative study, Renewable Energy 83 (2015) 527-542.

[26] OguzArslan (2010) "Exergoeconomic evaluation of electricity generation by the medium temperature 


\section{International Journal of Science and Research (IJSR) \\ ISSN (Online): 2319-7064}

Index Copernicus Value (2013): 6.14 | Impact Factor (2014): 5.611

geothermal resources using a Kalina cycle Simav case study" International journal of thermal sciences volume 49 pages $1866-1873$.

[27] Xinxin Zhang, Maogang He, Ying Zhang, A review of research on the Kalina cycle, Renewable and Sustainable Energy Reviews 16 (2012) 5309-5318.

[28] Eva Thorin, power cycles with ammonia-water mixtures as working fluid, doctoral thesis, 2000, ISSN 11043466.

[29] William D. Baasel (1990). Preliminary Chemical Engineering Plant Design (2nd ed.). Van Nostrand Reinhold. ISBN 0-442-23440-6, OCLC 1890713. 